\title{
Recursos construtivos na elaboração de produtos esportivos para prática de pole dance
}

\author{
Constructive resources in the development of sports products for pole dance \\ practice
}

\author{
CORRÊA, Silvia Maria \\ Universidade Estadual de Londrina, Graduada \\ correa.silviamaria@gmail.com \\ SILVA, Maria Antônia Romão da \\ Universidade Estadual de Londrina, Doutoranda \\ maria.antonia.romao@gmail.com \\ SOUZA, Patrícia de Mello \\ Universidade Estadual de Londrina, Doutora \\ patriciademellosouza@gmail.com
}

\section{RESUMO}

O presente artigo apresenta um projeto no qual foram utilizados recursos de construção em modelagem para o desenvolvimento de produtos em atendimento aos anseios físicos e emocionais das praticantes do Pole Dance. Uma vez que esta é considerada uma atividade física que mistura dança e ginástica e que exige força e resistência, suas praticantes necessitam de roupas que sejam adequadas à prática esportiva. Cabe, portanto, ao designer de moda investigar e projetar peças do vestuário que atendam às suas necessidades ergonômicas. Os dados apresentados foram coletados por meio de observação criteriosa e entrevista padronizada com professoras e alunas de um estúdio de dança especializado em Pole Dance localizado em uma cidade no Norte do Paraná. As peças foram projetadas com o auxílio de ferramentas de design voltadas para desenvolvimento de produtos do vestuário sugeridas por Sanches (2017); os recursos, as modelagens e os materiais foram devidamente testados considerando-se estética e funcionalidade. Comprovou-se que os produtos atenderam de forma satisfatória aos objetivos propostos, tendo sido identificados materiais têxteis que permitem a aderência do corpo à barra quando empregados nos pontos de contato. Identificou-se requisitos que devem ser considerados ao projetar esse tipo de vestuário.

Design de moda; vestuário esportivo; pole dance; ergonomia; recursos construtivos. 


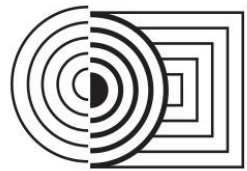

\section{$17^{\circ}$ ERGODESIGN \& USIHC 2019 \\ PUC-Rio, 11 a 13 de dezembro \\ Rio de Janeiro, RJ, Brasil}

$17^{\circ}$ Ergodesign - Congresso Internacional de Ergonomia e Usabilidade de Interfaces Humano Tecnológica: Produto, Informações Ambientes Construídos e Transporte

$17^{\circ}$ USIHC - Congresso Internacional de Ergonomia e Usabilidade de Interfaces Humano Computador

\begin{abstract}
The present article presents a project in which construction resources in modeling were employed for the development of products that would attend the physical and emotional needs of those who practice Pole Dance. Once that is considered a physical activity that mixes dance and gymnastics and that demands strength and resistance, those who practice it need clothes adequate to such sports practice. Thus, it is a fashion designer's duty to investigate and project develop garments that meet their ergonomic needs. The data hereby presented were collected through both careful observation and standardized interviews carried out with teachers and students from a Pole Dance studio located in a city in northern Paraná. Garments were designed with the help of design tools focused on apparel product development suggested by Sanches (2017); resources, moldings, and materials were properly tested taking into consideration aesthetics and functionality. It was proved that the products satisfactorily met the proposed objectives, having been identified textile materials that allow the body to adhere to the bar when used at the contact points. Identified requirements have to be considered when designing this type of clothing.
\end{abstract}

Fashion design; sports apparel; pole dance; ergonomy; constructive resources.

\title{
1. INTRODUÇÃO
}

Diversos são os tipos de esportes existentes e praticados pelo mundo. Dentre esses, estão os que empregam acrobacias e danças, além do uso de elementos ou suportes para a prática. $\mathrm{O}$ Pole Dance, como é conhecido atualmente, faz o uso da barra como instrumento para realização dos movimentos. A origem desse esporte não é clara, mas o início se deve às influências de algumas culturas em períodos e locais diferentes.

No Brasil, a prática da dança se popularizou recentemente: assim como outros tipos de esportes, é uma atividade que se modernizou com o passar dos anos e obteve uma série de vertentes diferentes. De acordo com Miho Cilense (2016) e Oliveira (2016) existem quatro modalidades de Pole Dance mais conhecidas na atualidade: o Pole Fitness, o Pole Exotic, o Pole Art e o Pole Street. Entretanto, as variações da atividade não alteraram sua essência principal, que é a realização de acrobacias com o uso de uma barra vertical.

Para as autoras citadas anteriormente, o Pole Fitness ou Pole Sport, pode ser definido como uma atividade semelhante à ginástica com foco nas acrobacias, de modo que o exercício contempla ganho de força e definição corporal. A modalidade requer alguns aprendizados para a execução dos movimentos, como as técnicas de: travas, giros, eixos, vetores de força, transições, inversões, figuras e quedas. Além disso, o Pole Fitness pode ser classificado como um jeito muito mais mecânico e acrobático de fazer Pole Dance.

Já a modalidade de Pole Street, segundo Oliveira (2016), tem como principal característica a prática em ambientes abertos com circulação de pessoas, como praças, parques ou locais que possam ter postes, árvores ou outras estruturas verticais que servem como mastro para se realizar os movimentos. As técnicas aplicadas nesta modalidade são semelhantes ou iguais às técnicas do Pole Fitness, de forma que se realiza uma mistura de movimentos acrobáticos com danças urbanas.

Para a execução dos movimentos, o corpo do atleta precisa ter força, flexibilidade e resistência (BALDIN; MENEGUCCI, 2017), pois é necessário promover o atrito entre o corpo e a barra. Com isso, afirmam Oliveira (2016) e Miho Cilense e Silva (2017; 2019), obtém-se uma 


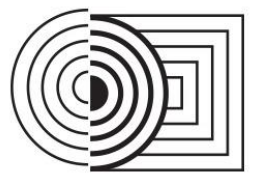

\section{$17^{\circ}$ ERGODESIGN \& USIHC 2019 \\ PUC-Rio, 11 a 13 de dezembro \\ Rio de Janeiro, RJ, Brasil}

$17^{\circ}$ Ergodesign - Congresso Internacional de Ergonomia e Usabilidade de Interfaces Humano Tecnológica: Produto, Informações Ambientes Construídos e Transporte

$17^{\circ}$ USIHC - Congresso Internacional de Ergonomia e Usabilidade

de Interfaces Humano Computador

aderência para a produção de movimentos corporais que se constituirão em uma dança, envolvendo elementos da ginástica e acrobacias circenses.

Isto posto, para a realização da atividade é necessário o uso de vestuário condizente com as necessidades da prática. Mediante a procura crescente pelo esporte, pesquisas como a de Baldin e Menegucci (2017) e Miho Cilense e Silva (2017; 2019) apontam a existência de uma lacuna na oferta de roupas em relação à demanda específica que não é atendida. Dentre os problemas levantados pelas autoras está o fato de que os produtos ofertados podem não ser os mais adequados, pois, uma modelagem mal projetada pode impedir a realização de movimentos ou, até mesmo, ocasionar lesões ao corpo do atleta.

Considera-se, portanto, que seja de responsabilidade do designer de moda investigar e projetar produtos adequados que solucionem possíveis problemas para a prática de Pole Dance (MIHO CILENSE; SILVA, 2017; 2019). Desta forma, o presente artigo apresenta um estudo acerca do uso de recursos construtivos de modelagem para o desenvolvimento de produtos de moda esportiva que atendam às necessidades físicas e emocionais das praticantes do Pole Dance.

Para o desenvolvimento do estudo, foi empregado as teorias do design emocional, de Norman (2008) e Jordan (1999 apud COSTA; TONETTO, 2011), para estruturar uma pesquisa de campo realizado mediante entrevista padronizada e observação da ação com as praticantes do esporte. As entrevistas foram conduzidas por meio de conversação direta e individual no dia 30 de abril de 2018 com três professoras e treze alunas de um estúdio especializado em Pole Dance na cidade de Londrina no Paraná.

As necessidades foram definidas após consulta e análise da bibliografia pesquisada sobre 0 assunto e a partir dos dados coletados nas entrevistas. Como base, foram utilizados os estudos de Miho Cilense (2016) e Miho Cilense e Silva $(2017 ; 2019)$ a respeito da ergonomia para o desenvolvimento do vestuário adequado para a prática de Pole Dance. Para projetar produtos direcionados às praticantes de Pole Dance, foram realizadas investigações e testes de recursos construtivos, técnicas de modelagem e materiais têxteis adequados às necessidades das praticantes do esporte.

\section{ASPECTOS ENVOLVIDOS NO PROCESSO DE MODELAGEM}

Para Souza (2006, p. 21), "a modelagem é a técnica responsável pelo desenvolvimento das formas da vestimenta, transformando materiais têxteis em produtos do vestuário".

Souza (2013) e Beduschi (2013) afirmam que existem alguns princípios básicos de conhecimento para a obtenção de bons resultados no processo de elaboração da modelagem, a saber: o corpo humano, a silhueta, os materiais, a manipulação do espaço e os recursos construtivos.

O corpo humano é caracterizado por ser a base tridimensional e o suporte para o produto: não é uniforme, de modo que possui saliências, curvas e concavidades propícias para moldar o material quando é sobreposto ao corpo. Conhecer a anatomia, a mobilidade do corpo, as proporções e o alcance das articulações é essencial para a projetação da modelagem (SOUZA, 2013). A silhueta, também chamada de shape, e completamente vinculada a esta análise corpórea, é a configuração expressa pelo volume ao redor do corpo, definindo, assim, seu 


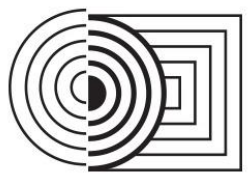

\section{$17^{\circ}$ ERGODESIGN \& USIHC 2019 \\ PUC-Rio, 11 a 13 de dezembro \\ Rio de Janeiro, RJ, Brasil}

$17^{\circ}$ Ergodesign - Congresso Internacional de Ergonomia e Usabilidade de Interfaces Humano Tecnológica: Produto, Informações Ambientes Construídos e Transporte

$17^{\circ}$ USIHC - Congresso Internacional de Ergonomia e Usabilidade de Interfaces Humano Computador

contorno. Desta forma, embora o conceito possa pressupor uma representação plana, a vestimenta requer a projeção tridimensional.

Tanto Souza (2013) quanto Beduschi (2013) mencionam o fato de que os materiais têxteis são decisivos na configuração das silhuetas: constituem-se como principal matéria-prima e apresentam características como peso, elasticidade, distorção, drapeabilidade, entre outras, que podem limitar o emprego para determinados usos.

No que se refere ao vestuário esportivo, os materiais variam de acordo com a demanda da modalidade esportiva, devido à relação direta com o ambiente onde a atividade é realizada, com o tipo de esforço, com a energia gasta, com a intensidade e a duração dos movimentos (FILGUEIRAS; ARAÚJO, 2016).

Outro aspecto importante quando se aborda o processo de modelagem de produtos é pensar a espacialidade, definida por Souza (2013), como o espaço existente entre o corpo e o material, que pode ser manipulado de modo a criar aproximação ou afastamento, determinando-se, assim, a configuração da silhueta. Revelar, insinuar ou ocultar a anatomia corporal pressupõe selecionar recursos de construção para modelar e, assim, elaborar a "embalagem" que envolve o corpo.

Para Souza e Menezes (2010, apud SOUZA, 2013), recursos construtivos são elementos que permitem estruturar a forma do produto, de modo a promover sustentação, ajuste ou configuração de volumes. Nessa perspectiva, as autoras definem que os produtos são caracterizados por volumes, planos ou linhas, que, utilizados sobre a superfície do corpo, podem ser elementos de intervenção e qualificação da superfície, criando texturas ou efeitos de luz e sombra.

Uma vez que a roupa é considerada o primeiro habitat do corpo, como se fosse uma segunda pele, afeta diretamente a qualidade e o modo de vida do usuário, interferindo, também, em suas sensações e percepções (SOUZA, 2006). Sabendo dessa relação, torna-se imprescindível entender quais são as necessidades ergonômicas dos consumidores para assim projetar produtos adequados para o uso. O estudo ergonômico é primordial para o desenvolvimento de qualquer vestuário e a investigação ocorre por meio do estudo das situações vivenciadas. Conforme lida (2005), para se ter bons resultados, deve-se estudar as situações de uso do produto antes, durante e após a atividade. O objetivo é trazer melhores condições para a vida do público, de forma a promover sua segurança e satisfação durante o uso e, também, à redução de erros ou acidentes.

A modelagem, portanto, deve ser projetada pensando na mobilidade e segurança do usuário, conforto tátil e térmico, além de agregar ao produto qualidades estéticas.

Pelo exposto, compreende-se a complexidade e as inúmeras possibilidades que envolvem o processo de construção de um produto vestível. $O$ ato de projetar caracteriza-se como um processo de relacionar as informações coletadas, sejam elas por estudo ou observação, com o ato de executar um produto na prática, dando-lhe atributos ergonômicos, funcionais e/ou estéticos, por meio da manipulação de elementos e instrumentos, para assim dar forma a um produto tridimensional passível de uso. 


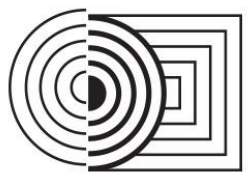

\section{$17^{\circ}$ ERGODESIGN \& USIHC 2019 \\ PUC-Rio, 11 a 13 de dezembro \\ Rio de Janeiro, RJ, Brasil}

$17^{\circ}$ Ergodesign - Congresso Internacional de Ergonomia e Usabilidade de Interfaces Humano Tecnológica: Produto, Informações Ambientes Construídos e Transporte

$17^{\circ}$ USIHC - Congresso Internacional de Ergonomia e Usabilidade de Interfaces Humano Computador

\section{REQUISITOS DE PROJETO}

A prática de Pole Dance exige a mobilidade do corpo, logo, deve-se considerar a necessidade de estudos voltados para a relação estabelecida entre corpo, movimento, barra e vestuário, para melhor compreender a relação existente entre o usuário, produto e o ambiente. $O$ direcionamento deste estudo possibilitou uma compreensão das percepções de parte do público praticante para, assim, projetar-Ihes experiências de forma a avaliar quais são as necessidades ergonômicas, funcionais e estético-simbólicas que devem ser consideradas ao projetar produtos do vestuário para a prática desse esporte.

O foco do estudo foi a elaboração de produtos do vestuário voltados para a modalidade de Pole Fitness e, se possível, também abranger a modalidade de Pole Street. Em virtude das atividades praticadas nesta modalidade, tornou-se fundamental definir as necessidades dos praticantes para realizar o esporte. Para tanto, baseou-se no estudo ergonômico realizado por Miho Cilense (2016), por esse definir as necessidades por meio da análise da tarefa e da observação em pesquisa de campo, de modo a detalhar a execução dos movimentos juntamente com a informação de como e onde o corpo toca e adere quando se pratica a modalidade. Para isso, alguns dos conceitos apresentados pela autora serão descritos na Figura 1 para melhor elucidar como é a atividade executada por uma pole dancer.

Figura 1 - Conceitos Pole Dance

\begin{tabular}{|c|c|}
\hline Termo & Conceito do termo \\
\hline $\begin{array}{l}\text { Barra/ Pole } \\
\text { Mastro }\end{array}$ & $\begin{array}{l}\text { Instrumento que se utiliza para realizar Pole Dance, seu material pode ser de aço } \\
\text { inoxidável, pode ser somente estática ou ter também a possibilidade de ser giratória. }\end{array}$ \\
\hline Aderência & $\begin{array}{c}\text { Compreende o contato do corpo com a barra, pode ser um ponto de contato, uma trava } \\
\text { ou movimento que precisa de parte específica do corpo para se realizar, } \\
\text { sem a aderência fica difícil executar a maioria dos movimentos. }\end{array}$ \\
\hline Trava & $\begin{array}{c}\text { É o modo que se adere o corpo à barra de uma maneira firme e segura. A trava é } \\
\text { composta de alavanca, distribuição de peso, força e conhecimento corporal. Existem } \\
9 \text { travas básicas, são inúmerasas variações e modificações delas que podem } \\
\text { ser realizadas pelas diferentes partes do corpo. }\end{array}$ \\
\hline Movimento & Compreende a ação de giro, acrobacia ou pose, realizada no pole ou envolta dele. \\
\hline Giro & $\begin{array}{l}\text { Usa a mão como ponto âncora e pode usar a outra como ponto de contato. } \\
\text { movimento é composto da saída do chão, giro e retorno ao chão, podendo ou } \\
\text { não ter o contato com alguma parte do corpo no chão durante o giro. }\end{array}$ \\
\hline Acrobacia & $\begin{array}{l}\text { Usa-se o corpo inteiro, para isso a pessoa precisa subir ou inverter na barra, } \\
\text { normalmente é realizado acima do chão, o corpo se trava na barra, dando sensação } \\
\text { de estar preso a ela ao realizar a acrobacia. }\end{array}$ \\
\hline Pose & $\begin{array}{l}\text { É a figura estática do corpo na barra, pode ser realizada no chão e } \\
\text { com a barra ou apenas na barra, como elementos aéreos. }\end{array}$ \\
\hline Combo & É a realização de várias acrobacias e/ou giros em sequência. \\
\hline $\begin{array}{l}\text { Elementos } \\
\text { de transição }\end{array}$ & ou e \\
\hline
\end{tabular}

Fonte: Elaborados pelas autoras (2019), baseado em Miho Cilense (2016), Miho Cilense e Silva (2017; 2019). 


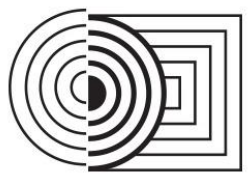

\section{$17^{\circ}$ ERGODESIGN} \& USIHC 2019

PUC-Rio, 11 a 13 de dezembro

Rio de Janeiro, RJ, Brasil $17^{\circ}$ Ergodesign - Congresso Internacional de Ergonomia e Usabilidade de Interfaces Humano Tecnológica: Produto, Informações Ambientes Construídos e Transporte

$17^{\circ}$ USIHC - Congresso Internacional de Ergonomia e Usabilidade de Interfaces Humano Computador

Com o propósito de abordar a necessidade de aderência do corpo na barra e a ergonomia que o produto esportivo deve contemplar, o estudo de Miho Cilense (2016), Miho Cilense e Silva (2017; 2019) contemplou 56 movimentos e 23 variações, somando 79 elementos. Dividiu-se o corpo em 9 regiões para explicar a relevância de cada parte; descreveu-se a quantidade de uso desta em porcentagem e quais são as travas básicas ou possíveis de usar, conforme apresenta a Figura 2.

Figura 2 - As 9 regiões do corpo

\begin{tabular}{|c|c|c|c|c|}
\hline \multicolumn{2}{|c|}{ Parte do corpo } & Descrição & Porcentagem & $\begin{array}{l}\text { Trava } \\
\text { Tontemnlara }\end{array}$ \\
\hline & Costas & $\begin{array}{c}\text { Área traseira do tronco do } \\
\text { ombro até a cintura }\end{array}$ & $5 \%$ & Trava de costas \\
\hline & Axila & Axila e o começo do braço & $15 \%$ & Trava de axila \\
\hline & Braço & $\begin{array}{l}\text { Interior do braço, do meio } \\
\text { do bíceps até o punho }\end{array}$ & $9 \%$ & $\begin{array}{l}\text { Trava de cotovelo, } \\
\text { trava de braço }\end{array}$ \\
\hline & Tronco & $\begin{array}{l}\text { Da linha do seios até o } \\
\text { começo da pélvis }\end{array}$ & $20,5 \%$ & Trava de costela \\
\hline & Mão & Punho e mão & $55 \%$ & Trava de mão \\
\hline & Entre pernas & $\begin{array}{c}\text { Final das nádegas, virilha } \\
\text { e começo da coxa }\end{array}$ & $13 \%$ & $\begin{array}{l}\text { Trava de coxa, } \\
\text { trava de glúteo }\end{array}$ \\
\hline & Coxa & Começo da coxa até sua metade & $32 \%$ & Trava de coxa \\
\hline & Perna & Da metade da coxa até o tornozelo & $37 \%$ & $\begin{array}{l}\text { Trava de coxa, } \\
\text { Trava de perna }\end{array}$ \\
\hline & Pé & Tornozelo e pé & $11,53 \%$ & Trava de pé \\
\hline
\end{tabular}

Fonte: Elaborado pelas autoras (2019), adaptado de Miho Cilense, 2016, Miho Cilense e Silva $(2017 ; 2019)$.

A partir das informações contidas na Figura 2 foi possível identificar as regiões do corpo nas quais ocorre o contato quando se pratica a atividade. Para projetar o vestuário destinado ao Pole Dance é preciso identificar e considerar as regiões do corpo que entram em contato com a barra para proporcionar a aderência, sendo esta, a ação fundamental para garantir a realização de uma trava com segurança e, como consequência, a promoção de movimentos praticados durante o Pole Dance.

Os aspectos funcionais do produto estão interligados aos ergonômicos e determinam a maneira que o produto deve ser projetado. Evidenciou-se a importância da antropometria dinâmica, que é a responsável por medir os alcances dos movimentos, de modo a garantir que a modelagem considere a relação que deve ser estabelecida entre a configuração formal e os movimentos realizados pelo corpo em cada uma das atividades. Isso significa considerar que cada parte do corpo não se move isoladamente, seja para pegar um objeto, executar o ato de vestir ou desvestir, entre outras ações (SOUZA, 2006). 


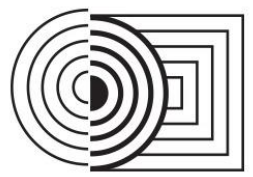

\section{$17^{\circ}$ ERGODESIGN \& USIHC 2019 \\ PUC-Rio, 11 a 13 de dezembro \\ Rio de Janeiro, RJ, Brasil}

$17^{\circ}$ Ergodesign - Congresso Internacional de Ergonomia e Usabilidade de Interfaces Humano Tecnológica: Produto, Informações Ambientes Construídos e Transporte

$17^{\circ}$ USIHC - Congresso Internacional de Ergonomia e Usabilidade de Interfaces Humano Computador

No que se refere aos materiais têxteis, existem algumas necessidades específicas que devem ser consideradas a fim de para proporcionar bem-estar ao praticante, como: conforto térmico, conforto tátil, mobilidade e aderência ao pole, além de possuir uma estética agradável para o usuário, por meio de cores, estampas ou algum beneficiamento.

Segundo Sissons (2012, apud BALDIN; MENEGUCCI, 2017), a malha é ideal para a confecção de artigos esportivos, que ocorre devido ao seu tipo de construção, que possibilita uma troca natural de calor com o ambiente, pois as laçadas formam pequenos espaços de ar. Além disso, a malha é um tecido que possui muita elasticidade e se adapta às formas do corpo humano.

Quanto às fibras dos tecidos, as que apresentam melhor relação com o vestuário esportivo são as sintéticas. Apesar de não serem biodegradáveis e de fonte renovável, possuem alta durabilidade e resistência, fácil manutenção, conforto tátil e térmico (DAHER, 2010).

O elastano, segundo Pezzolo (2007, apud BALDIN; MENEGUCCI, 2017), é uma fibra sintética muito utilizada nos artigos esportivos. Como a fibra possui características que se misturam facilmente a outras fibras, a combinação origina diversas possibilidades de variações na composição de um tecido, principalmente, dando-lhe a propriedade de elasticidade. Diante disso, a empresa têxtil DuPont registrou o elastano com o nome comercial de Lycra®.

No que se refere à aderência, Miho Cilense e Silva $(2017 ; 2019)$ apontam que não há variedade nas opções de materiais têxteis com a aderência similar à pele humana para se realizar alguns dos exercícios, uma vez que os movimentos são mais recorrentes embaixo dos braços e nas pernas. O material mais próximo que possa proporcionar essa aderência seria o tecido de vinil, entretanto, esse tipo de tecido se desgasta rapidamente e não atribui às roupas esportivas qualidades exigidas para o treino.

Mediante a observação das praticantes em atividade, foi possível verificar a vulnerabilidade e insegurança em relação a alguns produtos do vestuário utilizados no dia a dia pelas praticantes do esporte. Foram levantados outros fatores que devem ser considerados ao projetar produtos para a prática desse esporte, como: o suor que é produzido pelo corpo durante a atividade, pois o material deve proporcionar a respirabilidade e rápida secagem para não ocasionar incômodos ou outros problemas; o álcool utilizado para limpar a barra por meio de uma toalha de mão ou de rosto, porque pode haver contato com o material da roupa esportiva; a cola grip pode entrar em contato com o produto do vestuário, visto que é usada no corpo em regiões que se pretende usar como trava.

\section{APLICAÇÃO DE FERRAMENTAS, RESULTADOS E DISCUSSÃO}

Após o conteúdo gerado no trajeto projetual optou-se por utilizar algumas ferramentas com objetivo de organizar as informações e de impulsionar novas ideias para a geração de alternativas dos produtos a serem desenvolvidos.

O processo inicial de síntese do conteúdo do projeto ocorreu por intermédio do uso de duas ferramentas elaboradas por Sanches (2017), Diagrama REC ${ }^{2}$ e Diagrama de Objetivos em

\footnotetext{
${ }^{1}$ Cola grip pode ser líquida ou em pasta, sua composição é usada na pele para dar a possibilidade de aderência ao pole, assim a praticante consegue realizar travas sem escorregar.

2 Diagrama Radial de Exploração Contextual
} 


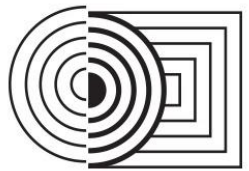

\section{$17^{\circ}$ ERGODESIGN \& USIHC 2019}

PUC-Rio, 11 a 13 de dezembro

Rio de Janeiro, RJ, Brasil $17^{\circ}$ Ergodesign - Congresso Internacional de Ergonomia e Usabilidade de Interfaces Humano Tecnológica: Produto, Informações Ambientes Construídos e Transporte

$17^{\circ}$ USIHC - Congresso Internacional de Ergonomia e Usabilidade de Interfaces Humano Computador

Fluxo (Figura 3). Ambas as ferramentas favoreceram a organização do fluxo de informação ao longo da etapa de geração de alternativas.

Figura 3 - Diagrama REC e Diagrama de Objetivos em Fluxo

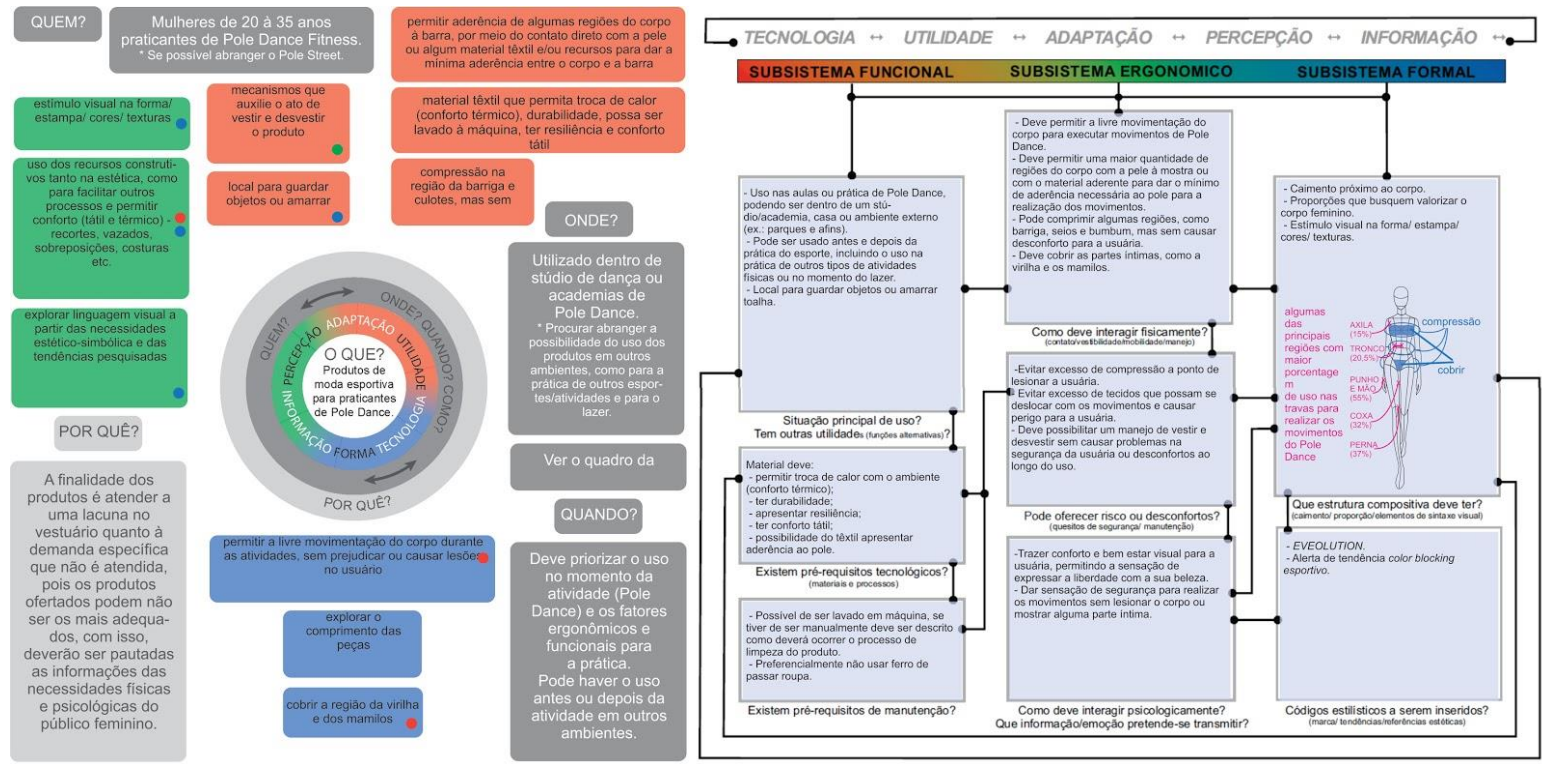

Fonte: Elaborado pelas autoras (2019), baseado em Sanches (2017).

A ferramenta REC foi configurada por meio das informações coletadas anteriormente e a geração de novos conceitos viáveis de serem trabalhados na elaboração de produtos esportivos para a prática de Pole Dance. Ressalta-se, no entanto, que nem todos os produtos irão abranger todos os conceitos definidos na ferramenta, contudo, alguns conceitos que são essenciais para a prática do esporte devem ser estritamente respeitados na delimitação dos produtos,como: permitir a livre movimentação do corpo durante as atividades sem prejudicar ou causar lesões no usuário; permitir aderência de algumas regiões do corpo à barra por meio do contato direto com a pele ou algum material têxtil e/ou recursos para dar a mínima aderência entre o corpo e a barra; entre outros.

O fluxograma auxiliou na organização das informações coletadas e geradas, também é perceptível uma distinção visual dos elementos e, ainda assim, uma conexão entre eles. Optouse em utilizá-la pelo fato de ampliar a inserção de conteúdos que não foram possíveis de serem aplicados no Diagrama REC. Entretanto, ambas ferramentas foram essenciais e puderam ser utilizadas para a concepção dos produtos.

As ferramentas escolhidas possibilitaram delimitar os aspectos e as características do projeto sem destoar do objetivo inicial proposto.Também foi preciso a realização da Persona e de pesquisas de tendências para nortear a geração de alternativas, com isso, utilizou-se as 


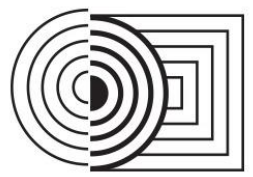

\section{$17^{\circ}$ ERGODESIGN \& USIHC 2019 \\ PUC-Rio, 11 a 13 de dezembro \\ Rio de Janeiro, RJ, Brasil}

$17^{\circ}$ Ergodesign - Congresso Internacional de Ergonomia e Usabilidade de Interfaces Humano Tecnológica: Produto, Informações Ambientes Construídos e Transporte

$17^{\circ}$ USIHC - Congresso Internacional de Ergonomia e Usabilidade de Interfaces Humano Computador

referências obtidas para compreender melhor o público alvo e de como o produto pode ser desenvolvido para a prática de Pole Dance.

Faz-se importante ressaltar que, devido à escassez de produtos no mercado específico para a prática Pole Dance, essas esportistas se valem de artigos comuns para a prática de ginástica em academias ou ao ar livre, como, por exemplo, uma bermuda, uma legging, um topper, que não correspondem às suas necessidades como praticantes do esporte. O projeto desenvolvido, portanto, considerou que houvesse um olhar singular do Design de Moda de acordo com o público local, isto é, das necessidades dos sujeitos dessa pesquisa em específico.

A partir de tal perspectiva e das informações coletadas foi possível conhecer quais as possibilidades de utilização desses tipos de materiais citados e dos recursos construtivos, além de suscitar a busca por outros beneficiamentos que possam atender as necessidades como a da aderência ou a de estética. Com isso, alguns testes foram realizados com a pretensão de verificar modelagens e materiais apropriados para a prática do esporte, sendo uma etapa essencial para a geração de alternativas da coleção, pois, somente assim, poderia se averiguar as possibilidades de construção dos produtos.

Foram testados adaptações na configuração dos produtos já utilizados pelas praticantes. $O$ estudo de modelagem foi realizado com molde de legging básica em três tamanhos $(P, M$ e $G)$ e com cós abaixo da linha da cintura; shorts a partir da modelagem da legging com cós até na linha da cintura e com elástico na barra para evitar que a mesma enrolasse no momento em que o usuário estivesse realizando a atividade.

Para o estudo de recortes na modelagem e a mistura de materiais, utilizou-se a modelagem básica da legging e, por meio do estudo das necessidades ergonômicas e funcionais realizadas neste projeto, delimitou-se regiões para aplicar outros materiais têxteis como experimento de aderência ao material do pole. Nesta etapa, testou-se: a associação do material supplex com a aplicação localizada de Poli Tape; combinação de supplex com recortes em couro sintético; combinação de supplex com recortes em supplex com textura emborrachada; combinação de supplex com recortes em tela antiderrapante.

Os resultados apontaram que a primeira proposta não é adequada. Enquanto a segunda combinação foi a que mais aderiu ao pole, entretanto, alguns ajustes deveriam ser realizados, como os locais onde devem constar os recortes, testes com outros tecidos que permitam maior respirabilidade e a utilização de outros tipos de recursos construtivos. A terceira combinação permitiu a realização de movimentos, porém não igual a segunda combinação, todavia, é possível realizar ajustes parecidos com os citados anteriormente. A quarta combinação permitiu aderência ao pole, mas seu material não possui elastano, com isso ocorreu esgarçamento e danificação do material têxtil, sendo este o único reprovado no teste.

Os testes foram realizados com auxílio das professoras de Pole Dance. A experimentação permitiu detectar quais materiais poderiam ou não ser utilizados, assim como, alterações necessárias às modelagens. Também possibilitou a análise de quais partes da roupa poderiam ser compostas com materiais aderentes e de que modo poderiam atrapalhar na execução de exercícios ou, ainda, prejudicar a praticante no instante de vestir ou desvestir o produto.

Portanto, para obter resultados compatíveis com o objetivo proposto, foi preciso utilizar as informações coletadas por intermédio da manipulação dos princípios elucidados anteriormente, 
$17^{\circ}$ ERGODESIGN \& USIHC 2019

PUC-Rio, 11 a 13 de dezembro

Rio de Janeiro, RJ, Brasil $17^{\circ}$ Ergodesign - Congresso Internacional de Ergonomia e Usabilidade de Interfaces Humano Tecnológica: Produto, Informações Ambientes Construídos e Transporte

$17^{\circ}$ USIHC - Congresso Internacional de Ergonomia e Usabilidade de Interfaces Humano Computador

como o corpo, os materiais, a silhueta, o espaço e, principalmente, os recursos construtivos. São esses princípios, afinal, que permitiram a atribuição de percepção no usuário ao utilizar o produto esportivo para Pole Dance.

A partir de tudo que foi estudado iniciou o processo de desenvolvimento dos protótipos, dos quais foram utilizados alguns dos pontos levantados com o uso das ferramentas. Na Figura 4 é possível observar três das composições desenvolvidas.

Figura 4 - Protótipos confeccionados

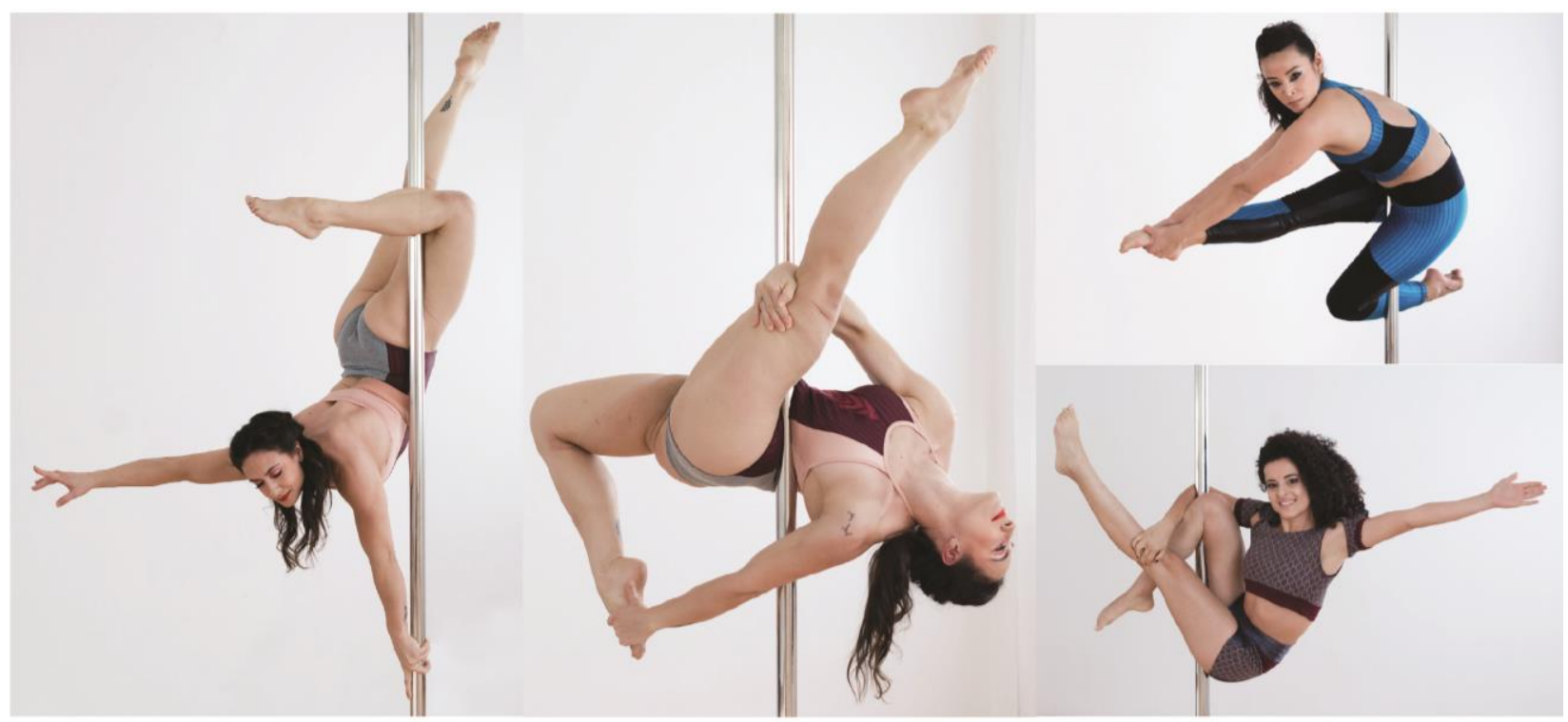

Fonte: Das autoras (2018).

Como consta na Figura 4, as composições desenvolvidas atenderam a grande maioria dos aspectos requisitados ao longo do projeto. O recurso mais utilizado nos produtos foram os recortes, esses que permitiram dar uma silhueta ao corpo feminino por meio da combinação de materiais têxteis e cores, possibilitando explorar o contraste ou a harmonia nas composições. Também, pode se dizer que este recurso permitiu a inovação ou o melhoramento de uma ideia utilizada como referência. Além disso, foi imprescindível a delimitação dos locais onde deveriam ter o contato da pele ou do produto aderente com o pole, de tal forma, os produtos confeccionados foram testados pelas participantes e, após os ajustes necessários, puderam ser utilizados para a prática de Pole Dance, como é possível observar pela figura acima.

\section{CONSIDERAÇÕES FINAIS}

Este trabalho teve como ponto central o desenvolvimento de moda esportiva específica para a prática de Pole Dance. O estudo das necessidades das praticantes foi fundamental para o levantamento de requisitos ergonômicos indispensáveis ao projeto de produtos do vestuário 


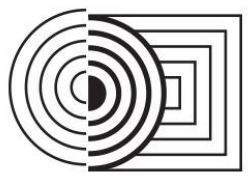

\section{$17^{\circ}$ ERGODESIGN \& USIHC 2019 \\ PUC-Rio, 11 a 13 de dezembro \\ Rio de Janeiro, RJ, Brasil}

$17^{\circ}$ Ergodesign - Congresso Internacional de Ergonomia e Usabilidade de Interfaces Humano Tecnológica: Produto, Informações Ambientes Construídos e Transporte

$17^{\circ}$ USIHC - Congresso Internacional de Ergonomia e Usabilidade

de Interfaces Humano Computador

direcionado para prática do esporte. Desse modo, foi possível determinar os fatores ergonômicos para projetar produtos do vestuário adequado aos movimentos realizados durante a prática do esporte, priorizando conforto, segurança e a satisfação do usuário.

O estudo da execução dos movimentos permitiu verificar quais as regiões do corpo necessitam estar em contato com a barra. Por meio de testes foi possível verificar recursos construtivos, modelagem e materiais têxteis adequados aos projetos de vestuário esportivo específico para o Pole Dance.

Foi constatado que alguns materiais podem permitir a aderência ao pole - exercem função semelhante a pele ao entrarem em contato com a barra -, mas o uso deve ser estratégico, como o uso em recortes localizados em partes específicas do produto. Isso ocorre devido à pouca elasticidade do material e a retenção de calor, que prejudica a respirabilidade da pele.

Os testes de modelagem asseguraram adequações necessárias que conferiram conforto e segurança aos usuários durante a realização dos movimentos, entre os quais é possível destacar folgas negativas que permitem maior compressão, o tamanho da área coberta pelo têxtil, recortes, fendas e aberturas estratégicas.

Importante salientar, que há uma escassez de pesquisas direcionadas ao desenvolvimento de produtos do vestuário voltados para Pole Dance e suas diferentes modalidades. Considera-se, desta forma, que o presente estudo levantou novas possibilidades formais e requisitos de projetos na busca por adequar o vestuário as necessidades ergonômicas dos praticantes desse esporte, além de expandir o estudo da relação estabelecida entre o corpo, os movimentos, a barra e o vestuário. Destaca-se, que os dados coletados ainda podem ser explorados mais intensamente tanto para propor discussões, como possibilitar novas explorações formal, funcional e tecnológica.

\section{REFERÊNCIAS BIBLIOGRÁFICAS}

BALDIN, Ana Elisa Contieri; MENEGUCCI, Franciele. Vestuário ergonômico para a prática de pole dance: o conforto térmico como requisito projetual. Projética, Londrina, v. 8, n. 2, p. 113126, out. 2017. Anual. Disponível em:

<http://www.uel.br/revistas/uel/index.php/projetica/article/view/27330>. Acesso em: 05 mar. 2018.

BEDUSCHI, Danielle Paganini. Diretrizes para o ensino de modelagem do vestuário. 2013. 202 f. Dissertação (Mestrado) - Curso de Têxtil e Moda, Escola de Artes, Ciências e Humanidades, Universidade de São Paulo, São Paulo, 2013. Disponível em: <http://www.teses.usp.br/teses/disponiveis/100/100133/tde-19022014-213611/pt-br.php>. Acesso em: 04 maio 2018.

COSTA, Filipe Campelo Xavier da; TONETTO, Leandro Miletto. Design Emocional:: conceitos, abordagens e perspectivas de pesquisa. Strategic Design Research Journal, São Leopoldo, v. 4, n. 3, p. 133-140, dez. 2011. Disponível em:

<https://www.researchgate.net/publication/273862410_Design_Emocional_conceitos_abordage ns_e_perspectivas_de_pesquisa>. Acesso em: 18 abr. 2018.

DAHER, Margareth Anna Zekveld. Materiais e processos têxteis. Londrina. 2010. p. 13-84

(Apostila da disciplina de Materiais Têxteis e Processos Têxteis). 
FILGUEIRAS, Araguacy Paixão Almeida; ARAÚJO, Maria do Socorro de. Design de Malhas Multifuncionais para Utilização em Vestuário Desportivo. Moda Palavra, S.I., v. 9, n. 17, p. 195221, jun. 2016. Disponível em:

<http://www.revistas.udesc.br/index.php/modapalavra/article/view/1982615x09172016195>. Acesso em: 17 maio 2018.

IIDA, Itiro. O que é a Ergonomia. In: Ergonomia: projeto e produção. 2.ed. São Paula: Edgar Blucher, 2005. p. 1-22.

MIHO CILENSE, lara Thereza Miho. Pole Dance: como atender as necessidades psicológicas do usuário e as necessidades físicas da prática. 2016. 173 f. Trabalho de Conclusão de Curso (Graduação) - Curso de Design de Moda, Ceca, Universidade Estadual de Londrina, Londrina, 2016.

MIHO CILENSE, lara Thereza; SILVA, Maria Antônia Romão da. Estudo ergonômico no desenvolvimento de vestuário adequado para prática de Pole Dance. In: CONGRESSO BRASILEIRO DE INICIAÇÃO CIENTÍFICA DE DESIGN E MODA, 10., 2017, Bauru, Anais do 13 Colóquio de Moda. Bauru: UNESP, 2017. p. 1-8. Disponível em: <http://www.coloquiomoda.com.br/anais/anais/13-Coloquio-deModa_2017/PO/po_6/po_6_Estudo_ergonomico_no_desenvolvimento.pdf>. Acesso em: 05 mar. 2018.

Estudo ergonômico no desenvolvimento de vestuário adequado para prática de pole dance. In MARTINS, Marcelo M.; SENA, Taísa Vieira (Org.). Congresso brasileiro de iniciação científica em design e moda (CBICDEM): coletânea de artigos apresentados em Bauru - 2017. Barueri: Estação das Letras e Cores, 2019. p 48-52

NORMAN, Donald A. Design emocional: por que adoramos (ou detestamos) os objetos do diaa-dia. Tradução de Ana Deiró. Rio de Janeiro: Rocco, 2008. 278 p. Tradução de: Emotional Design: why we love (or hate) everyday things.

OLIVEIRA, Andressa Karla da Silva. Pole dance: contextos e aproximações com os estudos de Rudolf Laban. 2016. 35 f. Trabalho de Conclusão de Curso (Licenciatura em Dança) Departamento de Artes, Universidade Federal do Rio Grande do Norte, Natal, 2016. Disponível em: <http://monografias.ufrn.br:8080/jspui/handle/123456789/2943>. Acesso em: 05 mar. 2018.

SANCHES, Maria Celeste de F. Moda e projeto: estratégias metodológicas em design. São Paulo: Estação das Letras e Cores, 2017. 240 p.

SOUZA, Patrícia de Mello. A modelagem tridimensional como implemento do processo de desenvolvimento do produto de moda. 2006. 113 f. Dissertação (Mestrado) - Curso de Pósgraduação em Desenho Industrial, Faculdade de Arquitetura, Artes e Comunicação, Universidade Estadual Paulista, Bauru, 2006. Disponível em: <http://200.145.6.238/handle/11449/96266>. Acesso em: 08 maio 2018.

SOUZA, Patrícia de Mello. Estratégias de construção para estruturas têxteis vestíveis. 2013. 190 f. Tese (Doutorado em Design) - Universidade Estadual Paulista. Faculdade de Arquitetura, Artes e Comunicação, Bauru. 2013. 